\title{
Modeling hemoglobin and hemoglobin:haptoglobin complex clearance in a non-rodent species- pharmacokinetic and therapeutic implications
}

\author{
Felicitas S. Boretti ${ }^{1}$, Jin Hyen Baek ${ }^{2}$, Andre F. Palmer ${ }^{3}$, Dominik J. Schaer ${ }^{4}$ and Paul W. Buehler ${ }^{2 * t}$ \\ ${ }^{1}$ Division of Veterinary Internal Medicine, School of Veterinary Medicine, University of Zurich, Zurich, Switzerland \\ ${ }^{2}$ Laboratory of Biochemistry and Vascular Biology, FDA Center for Biologics Evaluation and Research, Bethesda, MD, USA \\ ${ }^{3}$ Chemical and Biomolecular Engineering, The Ohio State University, Columbus, OH, USA \\ ${ }^{4}$ Division of Internal Medicine, University of Zurich Hospital, University of Zurich, Zurich, Switzerland
}

Edited by:

Magnus Gram, Lund University, Sweden

Reviewed by:

Magnus Gram, Lund University, Sweden

Bo Akerstrom, Lund University, Sweden

Åsa Jungner, Region Skåne, Sweden

*Correspondence:

Paul W. Buehler, Laboratory of Biochemistry and Vascular Biology,

Department of Hematology

Research and Review, FDA Center

for Biologics Evaluation and

Research, 29 Lincoln Drive,

Bethesda, MD 20850, USA

e-mail:paul.buehler@fda.hhs.gov

the findings and conclusions in this article have not been formally disseminated by the Food and Drug Administration and should not be construed to represent any Agency determination or policy.
Background: Haptoglobin $(\mathrm{Hp})$ prevents hemoglobin $(\mathrm{Hb})$ extravasation and attenuates $\mathrm{Hb}$ induced tissue oxidation and vasoconstriction. Small animal models such as mouse, rat and guinea pig appear to demonstrate proof-of-concept for $\mathrm{Hb}$ neutralization by $\mathrm{Hp}$ in diverse pre-clinical conditions. However, these species differ significantly from humans in the clearance of $\mathrm{Hb}: \mathrm{Hp}$ and demonstrate long persistence of circulating $\mathrm{Hb}: \mathrm{Hp}$ complexes.

Objective: The focus of this study is to understand $\mathrm{Hb}: \mathrm{Hp}$ clearance in a non-rodent species. In contrast to rodents, dogs maintain high plasma Hp concentrations comparable to humans and demonstrate more rapid clearance of $\mathrm{Hb}: \mathrm{Hp}$ when compared to rodent species, therefore dogs may represent a relevant species to evaluate $\mathrm{Hb}: \mathrm{Hp}$ pharmacokinetics and cellular clearance.

Results: In this study we show, that like human macrophages, dog peripheral blood monocyte derived macrophages express a glucocorticoid inducible endocytic clearance pathways with a high specificity for the $\mathrm{Hb}: \mathrm{Hp}$ complex. Evaluating the Beagle dog as a non-rodent model species we provide the first pharmacokinetic parameter estimates of free $\mathrm{Hb}$ and $\mathrm{Hb}: \mathrm{Hp}$ complexes. The data demonstrate a significantly reduced volume of distribution $\left(\mathrm{V}_{\mathrm{c}}\right)$ for $\mathrm{Hb}: \mathrm{Hp}$ compared to free $\mathrm{Hb}$, increased maximum plasma concentrations and areas under plasma concentration time curves (Cmax and AUC). Significantly reduced total body clearance $(C L)$ and a longer terminal half-life $\left(t_{1 / 2}\right)$ of approximately $12 \mathrm{~h}$ were also observed for the $\mathrm{Hb}$ : Hp complex. Distribution and clearance were identical for dimeric and multimeric $\mathrm{Hb}$ : Hp complexes. We found no significant effect of a high-dose glucocorticoid treatment protocol on $\mathrm{Hb}: \mathrm{Hp}$ pharmacokinetic parameter estimates.

Conclusion: Collectively, our study supports the dog as a non-rodent animal model to study pharmacological and pharmacokinetic aspects of Hb clearance systems and apply the model to studying $\mathrm{Hp}$ as a therapeutic in diseases of hemolysis.

Keywords: macrophage uptake, hemoglobin, haptoglobin, non-rodent, pharmacokinetic modeling

\section{INTRODUCTION}

Haptoglobin (Hp) therapy may be of benefit during hemolytic states to bind and sequester cell free hemoglobin $(\mathrm{Hb})$ within the vascular compartment (Schaer and Buehler, 2013). Hp decreases the interaction of $\mathrm{Hb}$ with critical organ systems and may attenuate free $\mathrm{Hb}$ triggered events such as vascular dysfunction and renal injury (Baek et al., 2012). Currently, plasma derived Hp is marketed in Japan with indications for trauma, burn and massive blood transfusion (Schaer et al., 2013). However, several off-label uses of $\mathrm{Hp}$ are reported in the literature as individual case studies or small clinical trials in various situations of acute hemolysis (Hashimoto et al., 1993; Yamamoto et al., 2000; Eda et al., 2001). Recent interest within Europe and the US to develop plasma derived $\mathrm{Hp}$ as a biologic therapeutic for uses in both acute and chronic hemolytic disease states have been suggested (Schaer et al., 2013). Therefore, understanding the pharmacologic and pharmacokinetic relevance of animal species for predicting human response is a critical aspect of the proof of concept and pre- clinical safety evaluation for Hp therapeutics in early development.

$\mathrm{Hp}$ is a $\alpha_{2}$-sialoglycoprotein and the primary $\mathrm{Hb}$-binding protein in plasma. Hp exists in humans as a multi-phenotype protein 
designated as Hp 1-1, Hp 2-1, and Hp 2-2 (Connell et al., 1962). Normal Hp concentrations in tissue and plasma are within a range between 0.5 and $2 \mathrm{mg} / \mathrm{ml}$ (Nosslin and Nyman, 1958; Levy et al., 2010). The dimeric (1-1) and the multimeric forms (2-1 and $2-2)$ of $\mathrm{Hp}$ contain identical $\beta$ globin chains involved in $\mathrm{Hb}$ dimer binding (Andersen et al., 2012), but differ in their $\alpha$ globin chains, which contain either one cysteine $(\alpha 1)$ or two cysteines $(\alpha 2)$ that are involved in disulfide bond formation (Connell et al., 1962; Smithies et al., 1962a,b). Therefore, the multi-phenotype designation is dependent on the proteins $\alpha 1$ and $\alpha 2$ content (Connell et al., 1962). Conflicting reports either do or do not support specific protective properties of Hp phenotypes (Lipiski et al., 2013; Asleh et al., 2014).

Clearance of $\mathrm{Hb}: \mathrm{Hp}$ complexes has been suggested to occur via tissue (spleen and liver) resident macrophages (Kristiansen et al., 2001; Schaer et al., 2007). These cells typically express a high surface concentration of CD163 and maximal heme oxygenase-1 (HO-1) enzymatic capacity (Zwadlo et al., 1987). CD163 is a cell surface protein exclusive to monocytes/macrophages and is the putative 9-domain receptor for binding and internalization of Hb:Hp complexes (Kristiansen et al., 2001). Further detoxification of heme takes place via HO-1 to liberate free iron, which is then bound to the ferritin complex until it is reutilized. Monocyte/macrophage clearance may be saturated when supra-physiological concentrations of $\mathrm{Hb}: \mathrm{Hp}$ complex result from therapeutic $\mathrm{Hp}$ administration during hemolysis and this may lead to extended circulation of $\mathrm{Hb}: \mathrm{Hp}$ within the vascular space. With interest in development of $\mathrm{Hp}$ as a biologic therapeutic it remains important to identify species with a "human-like" functional monocyte/macrophage Hb:Hp clearance system that could serve to model $\mathrm{Hb}: \mathrm{Hp}$ clearance in humans.

Our rationale for evaluating the dog as a model is based on several aspects of $\mathrm{Hb}$ clearance systems observed in canines that appear to approximate humans. For example, in contrast to rodents, human and dog have high basal plasma concentrations of Hp (Boretti et al., 2009). We previously reported that dogs are responsive to up-regulation of $\mathrm{Hp}$ following glucocorticoid dosing and this leads to attenuation of the acute effects of $\mathrm{Hb}$ exposure (Boretti et al., 2009). In these studies we observed, that glucocorticoid treated dogs exposed to cell free $\mathrm{Hb}$ accumulated high intravascular concentrations of $\mathrm{Hb}: \mathrm{Hp}$ complexes that were cleared within $24 \mathrm{~h}$. Based on these observations we hypothesized that the clearance system for cell free $\mathrm{Hb}$ in dogs may approximate that of humans. As a result the dog may estimate the pharmacokinetic response to supraphysiological Hb:Hp exposure and allow for evaluation of the pharmacokinetics of $\mathrm{Hb}$ following in vivo binding to differing $\mathrm{Hp}$ phenotypes.

The present study was designed to (1) characterize the Hb:Hp clearance system of dog macrophages in vitro based on the welldefined characteristics of the human system, (2) evaluate the effects of glucocorticoid pre-treatment on the pharmacokinetics of $\mathrm{Hb}$ and $\mathrm{Hb}: \mathrm{Hp}$ complexes in the dog and (3) evaluate the pharmacokinetics of $\mathrm{Hb}$ and $\mathrm{Hb}: \mathrm{Hp}$ complexes following the administration of two pre-clinical grade human Hps purified as dimeric or multimeric phenotype composition.

\section{MATERIALS AND METHODS MATERIALS}

Human and dog $\mathrm{Hb}$ was prepared using a standardized method previously described (Palmer et al., 2009). Human plasma fractionated $\mathrm{Hp}$ predominantly in the dimeric form (Hp 1-1) was provided by BioProducts Laboratory (Elstree, UK). Human plasma fractionated Hp predominantly in the multimeric forms (Hp 2-1 and Hp 2-2) was provided by CSL Behring (Kankakee, Illinois, USA). Concentrations of $\mathrm{Hb}$ and $\mathrm{Hp}$ solutions were prepared as 10 and $6 \mathrm{~g} / \mathrm{dl}$, respectively. Reducing and non-reducing gels were carried out according to existing protocols outlined by Life Technologies ${ }^{\mathrm{TM}}$ Protocols.

\section{PREPARATION OF DOG MACROPHAGES}

Mononuclear cells were prepared from heparin anti-coagulated beagle dog blood by Ficoll Paque centrifugation at $420 \mathrm{~g}$ for $25 \mathrm{~min}$. After washing twice in phosphate buffered saline (PBS) the $\mathrm{CD}_{14}{ }^{+}$monocytes were isolated from the mononuclear cell fraction by magnetic cell separation using anti-CD14 magnetic MACS beads (Miltenyi Biotec) according to the protocol provided by the manufacturer. The isolated $\mathrm{CD}_{1}{ }^{+}$monocytes were cultured on glass coverslips in DMEM medium containing 10\% fetal calf serum (FCS) in the presence of human M-CSF $(100 \mathrm{ng} / \mathrm{ml}$; Peprotech $)$ and dexamethasone $\left(2.5 \times 10^{-7} \mathrm{M}\right.$; Sigma $)$ as indicated. According to our previous work, this concentration of dexamethasone induces maximum induction of CD163 and $\mathrm{Hb}: \mathrm{Hp}$ uptake in human macrophages (Schaer et al., 2002). To evaluate the effect of dexamethasone treatment on $\mathrm{Hb}: \mathrm{Hp}$ endocytosis, macrophage were analyzed after $36 \mathrm{~h}$ in culture. We have previously used this protocol to establish the Hb:Hp uptake stimulation activity of glucocorticoid treatment in human PBMC derived macrophages, and the same cell culture protocol provided evidence for robust CD163 expression in mouse peritoneal macrophages (Schaer et al., 2001). To compare endocytosis capacity for human and $\operatorname{dog} \mathrm{Hb}: \mathrm{Hp}$ we used a longer cell culture protocol of 4 day (in the presence of M-CSF and dexamethasone). After longer culture periods macrophages have a more mature phenotype with maximum CD163 expression and high $\mathrm{Hb}: \mathrm{Hp}$ endocytic capacity (Schaer et al., 2006a; Kaempfer et al., 2011).

\section{FLUORESCENT LABELING OF HUMAN AND DOG Hp}

Dog Hp was from Lee Biosolutions (St. Louis, Missouri USA), human $\mathrm{Hp}$ of the dimeric Hp 1-1 phenotype was from BPL BioProducs Laboratory (Elstree, UK). Dog and human Hp were diluted in PBS pH 8.0 to a concentration of $4 \mathrm{mg} / \mathrm{ml} .2 \mathrm{mg} \mathrm{Hp}$ were incubated with $100 \mu \mathrm{g}$ Alexa Fluor 488 succinimidyl ester (NHS ester; Moelcular Probes) for $1 \mathrm{~h}$ in the dark at room temperature. Subsequently, non-bound dye was removed by a PD-10 desalting column (GE Healthcare).

\section{MEASUREMENT OF Hb:Hp ENDOCYTOSIS}

Endocytosis of $\mathrm{Hb}: \mathrm{Hp}$ complexes by dog macrophages was measured as reported previously by a modified fluorescent uptake assay (Schaer et al., 2002, 2008). In our previous work we established that labeling of $\mathrm{Hb}: \mathrm{Hp}$ complexes with Alexa 488 does not significantly affect endocytosis by CD163 (Schaer et al., 2002, 2006b). Dog macrophages were incubated Alexa 488 labeled dog 
or human $\mathrm{Hp} \pm$ (non-labeled) $\mathrm{Hb}$ at a concentration of $10 \mu \mathrm{g} / \mathrm{ml}$ in serum free DMEM medium for $30 \mathrm{~min}$ at $5 \% \mathrm{CO}_{2} / 37^{\circ} \mathrm{C}$. After incubation the cells were washed with PBS and fixed with $4 \%$ buffered formalin for $15 \mathrm{~min}$. Nuclei were stained with Hoechst 33342 DNA stain. From each sample (cover slip) 20 random widefield fluorescence images were acquired with a Zeiss Observer.Z1 microscope equipped with an Axiocam MRm camera and ZEN 2012 software (Carl Zeiss AG) at an optical magnification of 400x. All image acquisition parameters were set at fixed values for the whole study and no further image processing was applied before quantification. Digital image analysis was performed using Cell Profiler image analysis software (Broad Institute; www. cellprofiler.org) to (1) identify and count individual cells in the Hoechst nuclear stain channel and (2) to quantify Alexa488 fluorescence intensity per cell in the green channel image. Subtracted background values were determined with macrophage samples that have not been incubated with a fluorescent protein. Images for illustration were acquired as Z-stack optical section images from the identical samples using an Apotome. 2 image acquisition system at an optical magnification of 400x (Carl Zeiss AG). The final images were composed using Fiji/ImageJ software (http://fiji. sc/Fiji) with identical threshold values applied to all images.

\section{DESIGN OF ANIMAL STUDIES}

All studies were performed in accordance with the Swiss Academy of Medical Sciences ethical principles and guidelines for experiments on animals. The protocol for the study was reviewed and approved by the Swiss Institutional Animal Care and Use Committee as meeting the Swiss guidelines for laboratory animal use. The present study was conducted to evaluate plasma concentration vs. time data and pharmacokinetics following exogenous $\mathrm{Hb}$ exposure of $4 \mathrm{~g}$ to seven separate groups of beagle dogs. After implantation of a jugular cannula and recovery, conscious Beagle dogs were randomized to 1 of 7 groups as follows: (1) dog $\mathrm{Hb}, 4 \mathrm{~g}$ dose $(n=4)$; (2) human $\mathrm{Hb}, 4 \mathrm{~g}$ dose $(n=4) ;(3)$ prednisone pre-treated ( $50 \mathrm{mg} / \mathrm{kg}$, twice daily, 3 days) (MartinezSubiela et al., 2004) + Dog Hb, 4 g dose $(n=6)$; (4) prednisone pre-treated $(50 \mathrm{mg} / \mathrm{kg}$, twice daily, 3 days $)+$ human $\mathrm{Hb}, 4 \mathrm{~g}$ dose $(n=6)$; (5) human $\mathrm{Hb} 4 \mathrm{~g}$ dose + dimeric human $\mathrm{Hp}$, $4 \mathrm{~g}$ dose $(n=6)$; (6) human $\mathrm{Hb} 4 \mathrm{~g}$ dose + multimeric human $\mathrm{Hp}, 4 \mathrm{~g}$ dose $(n=6)$ and (7) prednisone pre-treated $(50 \mathrm{mg} / \mathrm{kg}$, twice daily, 3 days) (Martinez-Subiela et al., 2004) + human $\mathrm{Hb}, 4 \mathrm{~g}$ dose + multimeric Hp, $4 \mathrm{~g}$ dose $(n=6)$. Dosing regimen: Animals were first dosed over a $10 \mathrm{~min}$ period with a $4 \mathrm{~g}$ bolus of $\mathrm{Hb}(40 \mathrm{ml}$, concentration $10 \mathrm{~g} / \mathrm{dl})$ followed immediately by a $4 \mathrm{~g}$ dose of $\mathrm{Hp}$ dimeric or multimeric $(67 \mathrm{ml}$, concentration $6 \mathrm{~g} / \mathrm{dl}$ ) administered over a $10 \mathrm{~min}$ period. Whole blood $(1 \mathrm{ml})$ per sample was obtained from the jugular vein at baseline and post $\mathrm{Hb}$ and $\mathrm{Hp}$ dosing: $5 \mathrm{~min} ., 0.25,0.5,0.75,1.0,1.5$, 2.0, 2.5, 3, 3.5, 4.0, 5.0, 6.0, 8.0, 12, 16, 24, 32, 36, 48 and $60 \mathrm{~h}$. After the initial $24 \mathrm{~h}$ of blood collections, the jugular cannula was removed and blood sampling until $60 \mathrm{~h}$ was performed using a 21 gauge needle and syringe. After the $60 \mathrm{~h}$ collection animals were returned to their colony. Whole blood was collected in heparinized $3 \mathrm{ml}$ syringes, centrifuged at $4000 \mathrm{rpm}$ for $10 \mathrm{~min}$ and plasma was frozen at $-80^{\circ} \mathrm{C}$ until uv-visible spectrophotometry and size exclusion-high performance liquid chromatography analysis. The speed of centrifugation did not lead to hemolysis. All basal and final collection blood samples were free of extra-cellular $\mathrm{Hb}$ based on visual and spectral analysis.

\section{DETERMINATION OF PLASMA Hb CONCENTRATIONS}

Plasma collected at baseline from each animal served as the blank to correct for background interference and turbidity. Ferrous heme (oxy/deoxy), ferric heme, and hemichrome were determined on photodiode array spectrophotometer (Model 8453 Hewlet Packard, Palo Alto, CA). Spectral data was evaluated using a multi-component analysis based on the extinction coefficients for each species and total heme was calculated by adding these values (Winterbourn, 1985). The Plasma concentration time data are represented as plasma heme micro-molar concentration bound within $\mathrm{Hb}$ or $\mathrm{Hb}: \mathrm{Hp}$ vs. time in hours. Free and $\mathrm{Hp}$-bound $\mathrm{Hb}$ were determined in plasma $(50 \mu \mathrm{L})$ by size exclusion chromatography $(\mathrm{SEC})$ run on a BioSep-SEC-S3000 $(600 \times 7.5 \mathrm{~mm}) \mathrm{SEC}$ column (Phenomenex, Torrance, CA) attached to a Waters Delta 600 pump and Waters 2499 dual-wavelength detector, controlled by a Waters 600 controller using Empower ${ }^{\mathrm{TM}} 2$ software (Waters Corp., Milford, MA). Peak areas for $\mathrm{Hb}$ and $\mathrm{Hb}: \mathrm{Hp}$ obtained at $405 \mathrm{~nm}$ were recorded. Calculations for percent free $\mathrm{Hb}$ were determined as follows ( $\mathrm{Hb}$ peak area/total $\mathrm{Hb}+\mathrm{Hb}: \mathrm{Hp}$ peak areas) $\times 100=$ percent free $\mathrm{Hb}$. Heme concentrations from uvvisible spectrometry $\mathrm{x}$ percent free $\mathrm{Hb}=$ free $\mathrm{Hb}$ concentration (as $\mu \mathrm{M}$ heme). Similarly, $\mathrm{Hb}$ bound to $\mathrm{Hp}$ was calculated as follows (Hb:Hp peak area/total $\mathrm{Hb}+\mathrm{Hb}: \mathrm{Hp}$ peak areas $) \times 100=$ percent $\mathrm{Hb}$ bound to $\mathrm{Hp}$ ( $\mathrm{Hb}: \mathrm{Hp}$ ). Heme concentrations from uv-visible spectrometry $\times$ percent $\mathrm{Hb}: \mathrm{Hp}=\mathrm{Hb}$ concentration (as $\mu \mathrm{M}$ heme) bound to $\mathrm{Hp}$ ( $\mathrm{Hb}: \mathrm{Hp})$.

\section{PHARMACOKINETIC PARAMETER ESTIMATE EVALUATION}

A non-compartmental pharmacokinetic analysis was performed on unbound $\mathrm{Hb}$ (group 1) and $\mathrm{Hb}$ bound to $\mathrm{Hp}$ (groups 2 and 3). Plasma $\mathrm{Hb}$ concentrations using WinNonlin version 5.2.1, Pharsight company (St. Louis, Missouri). Pharmacokinetic estimates are expressed in tabular form as mean \pm SEM. Maximal plasma concentrations (Cmax) represent the greatest plasma concentration reached after dosing in each animal. Area under the plasma concentration time curve $\left(\mathrm{AUC}_{0-\text { inf }}\right)$ was estimated using the linear trapezoidal rule to the last measurable concentration $\left(\mathrm{AUC}_{0}\right.$-Clast $)$ where $\mathrm{C}_{\text {last }}$ is the last measurable plasma concentration. Extrapolation to infinity $\left(\mathrm{AUC}_{\text {Clast-inf }}\right)$ was calculated by dividing $\mathrm{C}_{\text {last }}$ by the negative value of the terminal slope $(k)$ of the log-linear plasma concentration-time curve. Thus, $\mathrm{AUC}_{0-\infty}$ is equal to the sum of $\mathrm{AUC}_{0-\text { Clast }}$ and $\mathrm{AUC}_{\text {Clast-inf. Additional }}$ parameters were calculated as follows: the plasma clearance (CL) was calculated as the dose divided by $\mathrm{AUC}_{0-\text { inf }}$, half-life $\left(\mathrm{t}_{1 / 2}\right)$ was calculated as $\ln (2) * \mathrm{Vc} / \mathrm{CL}$. Volumes of distribution of the central compartment $(\mathrm{Vc})$ are calculated as the product of dose (as heme equivalents) divided by Cmax.

\section{RESULTS \\ CHARACTERIZATION OF THE DOG MONOCYTE/MACROPHAGE Hb:Hp COMPLEX CLEARANCE SYSTEM}

To characterize the dog monocyte/macrophage system for clearance of $\mathrm{Hb}: \mathrm{Hp}$ complexes and to evaluate the potential validity 
of this animal model for studies with human Hp we have investigated two essential functions that are characteristic for the human monocyte/macrophage Hb:Hp clearance system. These characteristics are the glucocorticoid responsiveness of the human system and the specificity for uptake of $\mathrm{Hb}: \mathrm{Hp}$ complexes as opposed to free Hp (Kristiansen et al., 2001; Schaer et al., 2002; Vallelian et al., 2010). Figure 1A illustrates that after a short in vitro culture period of $36 \mathrm{~h}$ only minimal fluorescent dog $\mathrm{Hb}: \mathrm{Hp}$ is taken up by dog macrophages. In contrast strong complex endocytosis can be detected when the cells were pretreated with dexamethasone at a concentration of $2.5 \times 10^{-7} \mathrm{M}$. We have previously shown that this treatment regimen induces $\mathrm{Hb}: \mathrm{Hp}$ uptake capacity in human PBMC derived macrophages (Schaer et al., 2002). Comparable low endocytosis in untreated cells and strong glucocorticoid stimulation of endocytosis was also observed in similar experiments using human instead of dog Hp (not shown). Figure 1B shows quantitative dog Hb:Hp complex uptake data that were obtained with monocytes prepared from three different Beagles. Figure 2A illustrates the minimal uptake of free fluorescent human and dog Hp by macrophages that have been differentiated by M-CSF and

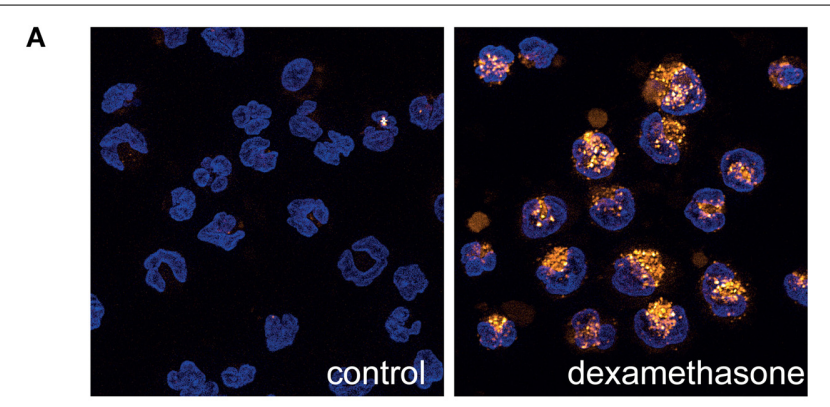

B

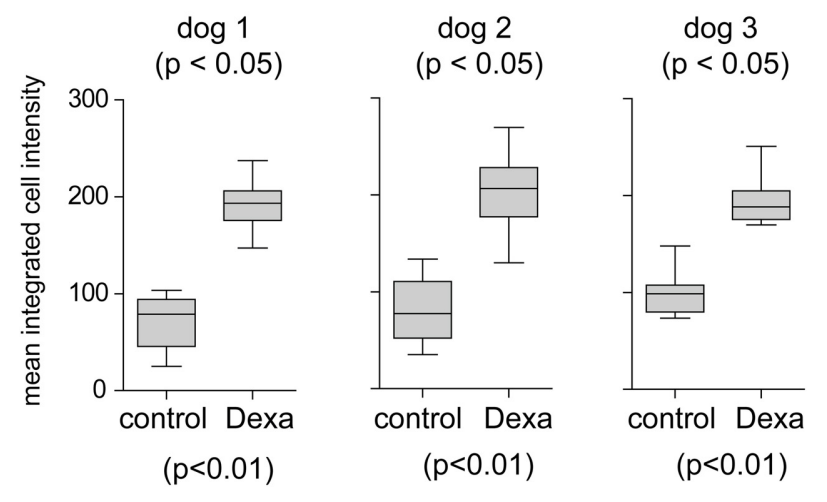

FIGURE 1 | Glucocorticoid induction of the dog macrophage $\mathrm{Hb}: \mathrm{Hp}$ clearance system. (A) Peripheral blood $\mathrm{CD}_{14}{ }^{+}$monocytes from beagle dogs were cultured for $36 \mathrm{~h}$ in the presence of M-CSF (control) or M-CSF + dexamethasone $\left(2.5 \times 10^{-7} \mathrm{M}\right)$ before they were incubated with

fluorescent dog $\mathrm{Hb}: \mathrm{Hp}$ complexes for $30 \mathrm{~min}$. Images represent maximum orthogonal projections of z-stack images acquired with an Apotome fluorescence microscopy system. Blue: nuclei; orange: $\mathrm{Hb}: \mathrm{Hp}$ complex. Original optical magnification 400x. (B) $\mathrm{Hb}$ :Hp upake was quantified by digital image analysis in control and dexamethasone treated macrophages from three different beagle dogs, each condition is represented by 15 individual random images. dexamethasone for 4 days to fully induce the clearance system. In contrast, both dog and human $\mathrm{Hp}$ are strongly endocytosed in the presence of equimolar concentrations of non-fluorescent human $\mathrm{Hb}$ (identical results were obtained with $\operatorname{dog} \mathrm{Hb}$, data not shown). The Hb:Hp complexes accumulate in the perinuclear intracellular compartment of the dog macrophages (Figure 2B). This observation supports the specificity of the dog clearance system for $\mathrm{Hb}: \mathrm{Hp}$ complexes. Figure 2C provides quantitative endocytosis data that have been obtained with macrophages prepared from five different beagle dogs. Comparison of the background corrected fluorescence signals may suggest that the dog $\mathrm{Hb}: \mathrm{Hp}$ complex is more efficiently taken up than the human $\mathrm{Hb}: \mathrm{Hp}$ complex. However, without more specific label free receptor-ligand interaction studies it is impossible to discriminate whether the relatively small difference reflects a true difference in $\mathrm{Hb}: \mathrm{Hp}$ endocytosis or whether it might be explained by slightly different labeling or different stability of the two labeled complexes in the lysosomal compartment of the dog macrophage. Apparently, this in vitro observation does not reflect different in vivo clearance of the two complexes.

The observation that both, dog and human Hb:Hp complexes are taken up by dog macrophages via a specific clearance system suggests that the dog might be an appropriate animal model to study systemic clearance of human plasma derived $\mathrm{Hp}$ therapeutics.

\section{PHARMACOKINETICS OF DOG AND HUMAN Hb IN BEAGLE DOGS}

To characterize potential differences in the pharmacokinetics of dog and human $\mathrm{Hb}$ following acute exposures in Beagles, purified dog $\mathrm{Hb}[4 \mathrm{~g}$ dose $(n=4)]$ and human $\mathrm{Hb}[4 \mathrm{~g}$ dose $(n=4)]$ was administered by bolus intravenous administration through the jugular vein. Blood sampling was performed to cover the range of plasma concentrations from Cmax until the absence of $\mathrm{Hb}$ in plasma. Table 1 shows the mean \pm SEM. pharmacokinetic parameter estimates for dog and human $\mathrm{Hb}$. Figure $\mathbf{3 A}$ shows the plot of mean \pm SEM plasma concentration vs. time data used to derive the pharmacokinetic parameters in Table 1. Data are fit to a single exponential decay and do not consider the differential kinetics of free $\mathrm{Hb}$ and $\mathrm{Hb}$ bound to the endogenous dog Hp. Both dog and human $\mathrm{Hb}$ demonstrate comparable pharmacokinetic parameters.

\section{PHARMACOKINETICS OF DOG AND HUMAN Hb FOLLOWING GLUCOCORTICOID UP-REGULATION OF ENDOGENOUS Hb CLEARANCE SYSTEMS}

To characterize the differences in the pharmacokinetics of free $\mathrm{Hb}$ and $\mathrm{Hb}$ bound to $\mathrm{Hp}$ ( $\mathrm{Hb}: \mathrm{Hp}$ complex) we repeated the above described study in glucocorticoid treated Beagles, which have maximally induced endogenous Hp. Dogs were pre-treated with prednisone ( $50 \mathrm{mg}$, twice daily, 3 days) based on our previous studies (Boretti et al., 2009) and the studies of others (Martinez-Subiela et al., 2004). On day 4 dogs were randomized to groups receiving dog $\mathrm{Hb}[4 \mathrm{~g}$ dose $(n=6)]$ or human $\mathrm{Hb}$ [4 g dose $(n=6)$ ] administered by bolus intravenous administration through the jugular vein. Blood sampling was performed to cover the range of plasma concentrations from Cmax until the absence of Hb:Hp in plasma. Table 2 shows the mean \pm SEM 
A
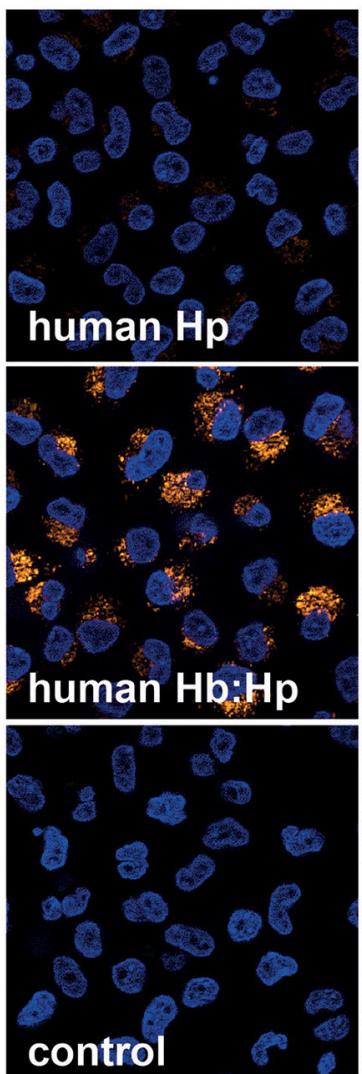

control
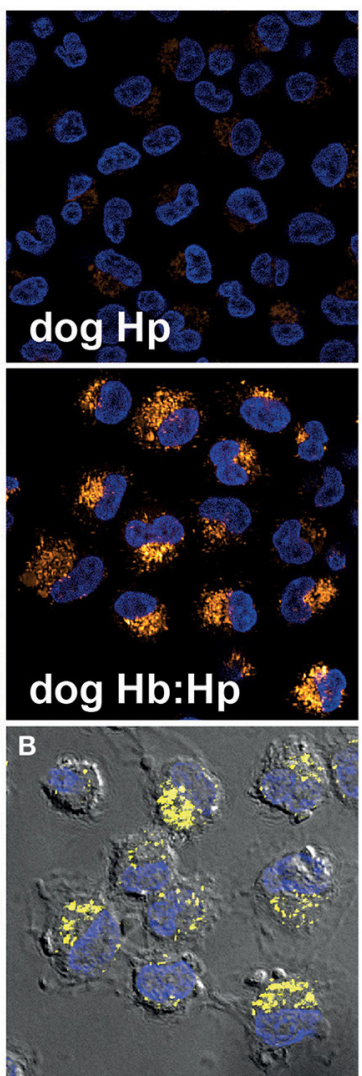

C

$$
p<0.05
$$

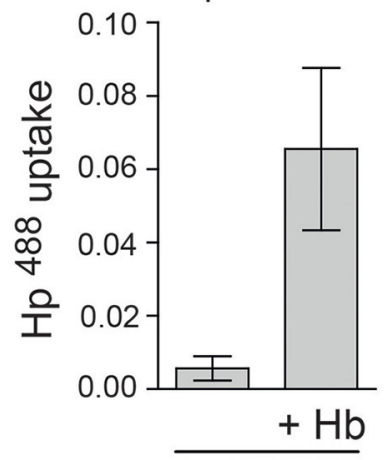

human $\mathrm{Hp}^{488}$

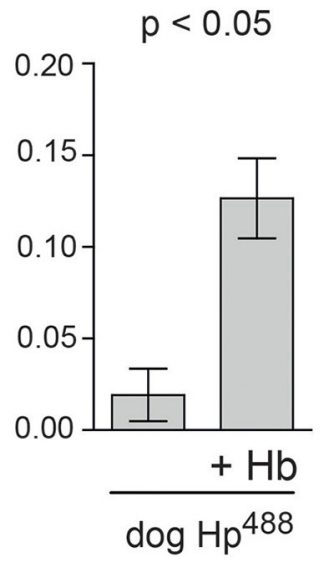

FIGURE 2 | Specificity of the dog macrophage clearance system for Hb:Hp complexes. (A) Peripheral blood CD14+ monocytes from beagle dogs were cultured for 4 days in the presence of M-CSF + dexamethasone $\left(2.5 \times 10^{-7} \mathrm{M}\right)$ before they were incubated with fluorescent (Alexa488) dog or human $\mathrm{Hp}$ with or without $\mathrm{Hb}$ for $30 \mathrm{~min}$. Images are single optical sections acquired with an Apotome fluorescence microscopy system. Blue: nuclei; Orange: $\mathrm{Hb}: \mathrm{Hp}$ complex. Original optical magnification 400x. (B) Fluorescence signals of a single optical apotome section as shown in (A) overlaid on a DIC bright-field image, which indicates cell boarders and intracellular localization of the endocytosed $\mathrm{Hb}$ : $\mathrm{Hp}$ complexes in the perinuclear region of the macrophages. Blue: nuclei; Yellow: $\mathrm{Hb}: \mathrm{Hp}$ complex. (C) Dog and human $\mathrm{Hp} \pm \mathrm{Hb}$ uptake was quantified by digital image analysis in macrophages from five different beagle dogs. pharmacokinetic parameter estimates for dog and human $\mathrm{Hb}$ unbound and bound to endogenous Hp. Figure 3B shows the plot of mean \pm SEM plasma concentration vs. time data for dog $\mathrm{Hb}$, while Figure 3C shows the plot of mean \pm SEM plasma concentration vs. time data for human $\mathrm{Hb}$ used to derive the pharmacokinetic parameters shown in Table 2. Data are fit to a single exponential decay and demonstrate that both dog and human $\mathrm{Hb}$ are comparably bound to the glucocorticoid enhanced endogenous dog $\mathrm{Hp}$ in vivo. Pharmacokinetic parameters of dog and human $\mathrm{Hb}$ not bound to $\mathrm{Hp}$ demonstrate a low exposure (Cmax and AUC), rapid CL and large Vc that expands beyond the central compartment. This observation may be due to renal distribution of unbound $\mathrm{Hb}$, as hemoglobinuria was observed following $\mathrm{Hb}$ exposure in the absence of $\mathrm{Hp}$ up-regulation or $\mathrm{Hp}$ administration, consistent with previous studies (Boretti et al., 2009; Lipiski et al., 2013). Both dog and human Hb bound to Hp demonstrate comparable exposures (Cmax and AUC) and significantly reduced $\mathrm{CL}$ compared to unbound $\mathrm{Hb}$. The $\mathrm{Vc}$ reflects the volume of the central compartment in the Beagle and demonstrates that the $\mathrm{Hb}: \mathrm{Hp}$ complex remains sequestered within the circulating blood volume. The $t_{1 / 2}$ of the endogenous dog $\mathrm{Hp}$ complex with dog or human $\mathrm{Hb}$ is highly comparable. The small differences in Cmax and Vc observed at low plasma concentrations of unbound dog and human $\mathrm{Hb}$ may suggest minor differences in $\mathrm{Hb}$ binding immediately after dosing. However, the contribution to overall pharmacokinetic exposure was not changed.

Collectively, these data suggest differences in distribution, exposure and clearance of free $\mathrm{Hb}$ and the $\mathrm{Hb}: \mathrm{Hp}$ complex, and demonstrate that dog and human $\mathrm{Hb}$ follow similar pharmacokinetics in Beagles when bound to Hp.

\section{PHARMACOKINETICS OF HUMAN Hb FOLLOWING ADMINISTRATION OF DIMERIC OR MULTIMERIC Hp}

In a next study we characterized the pharmacokinetics of $\mathrm{Hb}$ following administration of dimeric (primarily 1-1) and multimeric (2-1 and 2-2) human plasma derived Hp. These data should identify potential $\mathrm{Hp}$ phenotypic differences in exposure, distribution and clearance after acute dosing. Furthermore, these data allowed us to test for equivalence of dog and human $\mathrm{Hb}: \mathrm{Hp}$ clearance in Beagles. Dogs were randomized to groups administered $4 \mathrm{~g}$ human $\mathrm{Hb}$ followed by dimeric human $\mathrm{Hp}, 4 \mathrm{~g}$ dose $(n=6)$ or $4 \mathrm{~g}$ human $\mathrm{Hb}$ followed by multimeric human $\mathrm{Hp}, 4 \mathrm{~g}$ dose $(n=6)$. All proteins were administered by bolus intravenous administration through the jugular vein. Blood sampling was performed to cover the range of plasma concentrations from Cmax until the absence of Hb:Hp in plasma. Table 3 shows the mean \pm SEM pharmacokinetic parameter estimates for free human $\mathrm{Hb}$ and the different $\mathrm{Hb}: \mathrm{Hp}$ complexes that formed in vivo. Figure 4A shows the plot of mean \pm SEM plasma concentration vs. time data for $\mathrm{Hb}$ following dimeric $\mathrm{Hp}$ dosing, while Figure 4B shows the plot for mean \pm SEM plasma concentration vs. time data for $\mathrm{Hb}$ following multimeric $\mathrm{Hp}$ dosing. Derived pharmacokinetic parameters are shown in Table 3. Data are fit to a single exponential decay and demonstrate that $\mathrm{Hb}$ is comparably bound to dimeric and multimeric $\mathrm{Hp}$ in vivo. Pharmacokinetic parameters of $\mathrm{Hb}$ bound to dimeric and multimeric $\mathrm{Hp}$ demonstrate 
Table 1 | Pharmacokinetic parameters of dog and human hemoglobin $(\mathrm{Hb})(\mathrm{mean} \pm \mathrm{SEM})$ in Beagles.

\begin{tabular}{|c|c|c|c|c|c|}
\hline Hemoglobin [heme] & $C_{\max }(\mu \mathrm{mol} / \mathrm{L})$ & $A U C_{0-\text { infinity }}\left(h^{*} \mu \mathrm{mol} / \mathrm{L}\right)$ & CL (L/h) & $V c(\mathrm{~L})$ & $t_{1 / 2}(\mathrm{~h})$ \\
\hline Dog Hb (total) & $358.3 \pm 43.2$ & $2075 \pm 391$ & $0.1353 \pm 0.0265$ & $0.7359 \pm 0.106$ & $3.936 \pm 0.361$ \\
\hline Human Hb (total) & $377.2 \pm 18.3$ & $1929 \pm 148$ & $0.1319 \pm 0.0100$ & $0.667 \pm 0.035$ & $3.537 \pm 0.148$ \\
\hline
\end{tabular}
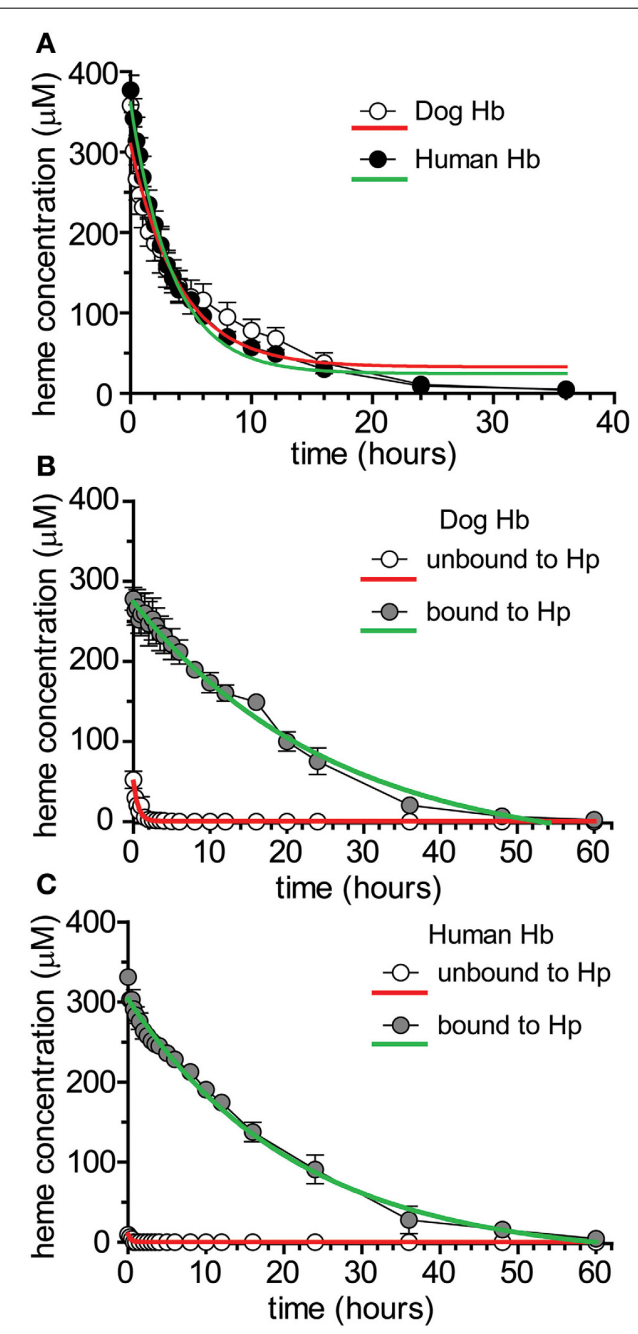

FIGURE 3 | Pharmacokinetics of dog and human $\mathrm{Hb} \pm$ glucocorticoid up-regulation of $\mathbf{H b}$ clearance systems. (A) Mean \pm SEM plasma concentration vs. time plotted for dog and human purified $\mathrm{Hb}$ administered to beagle dogs ( $n=4 /$ treatment). Data are fitted to a single exponential decay (red and green traces) and represent total heme bound to $\mathrm{Hb}+$ $\mathrm{Hb}: \mathrm{Hp}$. Pharmacokinetic parameter estimates are shown in Table 1. (B) Mean \pm SEM plasma concentration vs. time plotted for prednisone pre-treated Beagle dogs administered purified dog $\mathrm{Hb}(n=6)$. Data represent unbound and $\mathrm{Hp}$ bound concentrations in plasma. Data are fitted to a single exponential decay and represent total heme bound to $\mathrm{Hb}+$ $\mathrm{Hb}:$ Hp. Pharmacokinetic parameter estimates are shown in Table 2. (C) Mean \pm SEM plasma concentration vs. time plotted for prednisone pretreated Beagle dogs administered purified human $\mathrm{Hb}(n=6)$. Data represent unbound and $\mathrm{Hp}$ bound concentrations in plasma. Data are fitted to a single exponential decay (red and green traces) and represent total heme bound to $\mathrm{Hb}+\mathrm{Hb}: \mathrm{Hp}$. Pharmacokinetic parameter estimates are shown in Table 2. a comparable exposure (Cmax and AUC), significantly slower $\mathrm{CL}$ and a contracted Vc compared to unbound $\mathrm{Hb}$. The $\mathrm{t}_{1 / 2}$ of the $\mathrm{Hb}: H p$ dimeric and multimeric complex is highly comparable in Beagles. These data support that dimeric and multimeric $\mathrm{Hb}: \mathrm{Hp}$ complexes demonstrate similar in vivo pharmacokinetics. Overall, the pharmacokinetic parameters of both human $\mathrm{Hp}$ complexes are highly comparable to the parameter estimates for dog Hb:Hp complexes (Tables 2, 3). The plasma concentration vs. time curves shown in Figures 4A,B demonstrate two distinct phases. We speculate that this observation may be the result of CD163 availability on the surface of monocytes and macrophages over the duration of the experiment.

\section{PHARMACOKINETICS OF Hb:Hp COMPLEXES IN GLUCOCORTICOID TREATED DOGS}

In vitro and in vivo stimulation of human peripheral blood monocyte CD163 by glucocorticoids leads to increased uptake of $\mathrm{Hb}: \mathrm{Hp}$ complexes and we have demonstrated a comparable response of dog monocytes. To test the contribution of the glucocorticoid inducible CD163 pool on in vivo pharmacokinetics we evaluated the clearance of $\mathrm{Hb}: \mathrm{Hp}$ complexes in animals that have been pre-treated with $50 \mathrm{mg}$ prednisone, twice daily for 3 consecutive days, which corresponds to a dose of $7-10 \mathrm{mg} / \mathrm{kg} / \mathrm{day}$. We have previously shown in human patients with acute inflammatory and autoimmune diseases that comparable immunosuppressive glucocorticoid treatment protocols stimulate strong CD163 expression and $\mathrm{Hb}: \mathrm{Hp}$ endocytosis capacity in peripheral blood monocytes (Vallelian et al., 2010). Six dogs were dosed with human $\mathrm{Hb}(4 \mathrm{~g})$ and multimeric human $\mathrm{Hp}(4 \mathrm{~g})$. Blood sampling was performed to cover the range of plasma concentrations from Cmax until the absence of $\mathrm{Hb}: \mathrm{Hp}$ in plasma. Table 4 shows the mean \pm SEM pharmacokinetic parameter estimates for $\mathrm{Hb}$ unbound and bound to Hp. Figure 4C shows the plot of mean \pm SEM plasma concentration vs. time data for $\mathrm{Hb}$ in the unbound and $\mathrm{Hp}$ bound forms used to derive pharmacokinetic parameters shown in Table 4. Data are fit to a single exponential decay and demonstrate that $\mathrm{Hb}$ is entirely bound to $\mathrm{Hp}$ in vivo. This is the result of both high endogenous $\mathrm{Hp}$ induced by prednisone and exogenously administered human $\mathrm{Hp}$. Pharmacokinetic values for $\mathrm{Hp}$ bound $\mathrm{Hb}$ show comparable values in all studies regardless of the $\mathrm{Hp}$ species and demonstrate comparable exposures (Cmax and AUC) and rates of CL for untreated and glucocorticoidtreated dogs (Tables 2-4). Collectively, the data demonstrates that glucocorticoid stimulation of CD163 in vivo does not contribute more rapid clearance of $\mathrm{Hb}: \mathrm{Hp}$. The explanation for this observation is likely that the large pool of resident macrophages in the liver and spleen constitutively express high levels of CD163, which cannot be further stimulated by glucocorticoid administration. Compared to this large pool of $\mathrm{CD}_{163}{ }^{+}$resident spleen and 
Table 2 | Pharmacokinetic parameters of dog and human $\mathrm{Hb}(+)$ prednisone (mean $\pm \mathrm{SEM}$ ) in Beagles.

\begin{tabular}{|c|c|c|c|c|c|}
\hline Hemoglobin [heme] & $C_{\max }(\mu \mathrm{mol} / \mathrm{L})$ & $\mathrm{AUC}_{0 \text {-infinity }}\left(\mathrm{h}^{*} \mu \mathrm{mol} / \mathrm{L}\right)$ & $\mathrm{CL}(\mathrm{L} / \mathrm{h})$ & $V c(\mathrm{~L})$ & $t_{1 / 2}(h)$ \\
\hline Dog $\mathrm{Hb}$ (bound) & $277.9 \pm 14.3$ & $4798 \pm 405$ & $0.05405 \pm 0.00463$ & $0.912 \pm 0.0493$ & $12.05 \pm 1.04$ \\
\hline Human $\mathrm{Hb}$ (bound) & $353.7 \pm 18.0$ & $5457 \pm 185.2$ & $0.03538 \pm 0.00305$ & $0.7562 \pm 0.0172$ & $11.45 \pm 0.527$ \\
\hline
\end{tabular}

(Unbound) and (bound) to Hp.

Table 3 | Pharmacokinetic parameters of $\mathrm{Hb}$ bound to dimeric and multimeric $\mathrm{Hp}$ (mean $\pm \mathrm{SEM}$ ) in Beagles.

\begin{tabular}{|c|c|c|c|c|c|}
\hline Hemoglobin [heme] & $C_{\max }(\mu \mathrm{mol} / \mathrm{L})$ & $\mathrm{AUC}_{0 \text {-infinity }}\left(\mathrm{h}^{*} \mu \mathrm{mol} / \mathrm{L}\right)$ & CL (L/h) & $V c(\mathrm{~L})$ & $t_{1 / 2}(\mathrm{~h})$ \\
\hline \multicolumn{6}{|l|}{ DIMERIC Hp } \\
\hline Human $\mathrm{Hb}$ (unbound) & $54.14 \pm 4.95$ & $78.63 \pm 16.9$ & $3.711 \pm 0.862$ & $5.022 \pm 0.463$ & $1.034 \pm 0.139$ \\
\hline \multicolumn{6}{|l|}{ MULTIMERIC Hp } \\
\hline Human $\mathrm{Hb}$ (unbound) & $78.67 \pm 2.82$ & $64.89 \pm 17.8$ & $5.156 \pm 1.30$ & $3.193 \pm 0.109$ & $0.5640 \pm 0.132$ \\
\hline
\end{tabular}

(Unbound) and (bound) to Hp.

liver macrophages, the highly glucocorticoid responsive pool of peripheral blood monocytes is small and appears to provide a minor contribution to systemic $\mathrm{Hb}: \mathrm{Hp}$ clearance. The predominant distribution of $\mathrm{CD} 63^{+}$monocytes and macrophages to liver and spleen is demonstrated in both rodent and non-rodent species (Granfeldt et al., 2013).

\section{PLASMA PROFILES OF BOUND Hb:Hp COMPLEXES}

Figure 5 (bottom panel) shows the SEC elution profiles of standard $\mathrm{Hb}$ and $\mathrm{Hb}: \mathrm{Hp}$ complexes. Human and dog $\mathrm{Hb}$ demonstrate an elution time of $20.7 \mathrm{~min}$. Dog $\mathrm{Hb}: \mathrm{Hp}$ demonstrates an elution time of $17.7 \mathrm{~min}$. Dog $\mathrm{Hp}$ is entirely in the dimeric form, but likely differs from human dimeric $\mathrm{Hp}$ in terms of the extent and distribution of glycosylation sites. This is observed in the chromatographic elution profile of dimeric human $\mathrm{Hb}: \mathrm{Hp}$, which elutes approximately 0.5 min faster than $\mathrm{Hb}$ bound $\mathrm{dog}$ $\mathrm{Hp}$ and indicates a slightly larger molecular size for the human Hb:Hp complex. Multimeric human Hp shows a broad elution profile between 12 and $16 \mathrm{~min}$ and no dimeric Hp phenotype. Figure 5 (bottom panel, inset) shows a gel electrophoresis of dimeric and multimeric $\mathrm{Hp}$ preparations under non-reducing and reducing conditions. The non-reducing gel shows the phenotype specific dimer-polymer distribution of the Hp products used in our studies. The reducing gel shows the presence of primarily $\alpha 1$ globin in dimeric $\mathrm{Hp}$ and $\alpha 2$ globin in multimeric Hp preparations. Figure 5 (middle panel) shows representative plasma samples from prednisone pre-treated animals following $\mathrm{Hb}$ exposure \pm multimeric $\mathrm{Hp}$. The elution time peak at $17.7 \mathrm{~min}$ represents prednisone induced dog $\mathrm{Hp}$ bound to $\mathrm{Hb}$ in both chromatograms (prednisone $\pm \mathrm{Hp}$ ). The elution time of multimeric $\mathrm{Hp}: \mathrm{Hp}$ is observed with primary peaks at 14.7 and $15.1 \mathrm{~min}$. The smaller area of the multimeric $\mathrm{Hb}: \mathrm{Hp}$ peak is consistent with the large area of the dimeric dog Hp following prednisone pre-treatment. Figure 5 (top panel) shows the distribution of
$\mathrm{Hb}$ bound to $\mathrm{Hp}$ after dimeric and multimeric human Hp dosing. Samples show elution times of $\mathrm{Hp}$ bound $\mathrm{Hb}$ consistent with purified standards. Samples represent the $1 \mathrm{~h}$ collection time point.

\section{DISCUSSION \\ PRIMARY FINDINGS}

Here we present in vitro data, which suggests that the function and fundamental regulatory pathways of the human and dog macrophage clearance system for $\mathrm{Hb}: \mathrm{Hp}$ complexes are comparable. These in vitro observations strongly indicate that human and dog demonstrate similar pharmacologic and pharmacokinetic responses to intravascular $\mathrm{Hb}: \mathrm{Hp}$ exposure and that dog may, therefore, be an appropriate model for the pre-clinical characterization of $\mathrm{Hp}$ therapeutics.

We provide the first pharmacokinetic parameter estimates of cell free $\mathrm{Hb}$ and its modulation by $\mathrm{Hp}$ therapeutics in a nonrodent model. The data reflect a drastically reduced Vc of the complex compared to free $\mathrm{Hb}$, increased exposures (Cmax and AUC) and significantly reduced CL with a $t_{1 / 2}$ of approximately $12 \mathrm{~h}$. These estimates were not significantly different for the human and dog proteins, respectively. These data support the concept whereby a major protective function of $\mathrm{Hp}$ is provided by a limited expansion of the central compartment volume (Vc) and as a result decreased tissue compartmentalization of free $\mathrm{Hb}$.

Our in vivo pharmacokinetic studies suggest two additional key findings.

First, the pharmacokinetics of $\mathrm{Hp}$ bound $\mathrm{Hb}$ following the administration of dimeric and multimeric plasma derived human Hp demonstrate comparable pharmacokinetic parameter estimates. These data suggest that both $\mathrm{Hb}$ bound to dimeric and multimeric $\mathrm{Hp}$ undergo similar handling by Beagle dog $\mathrm{Hb}$ clearance pathways. Earlier in vitro studies have provided conflicting data on differential uptake and post-endocytic processing 

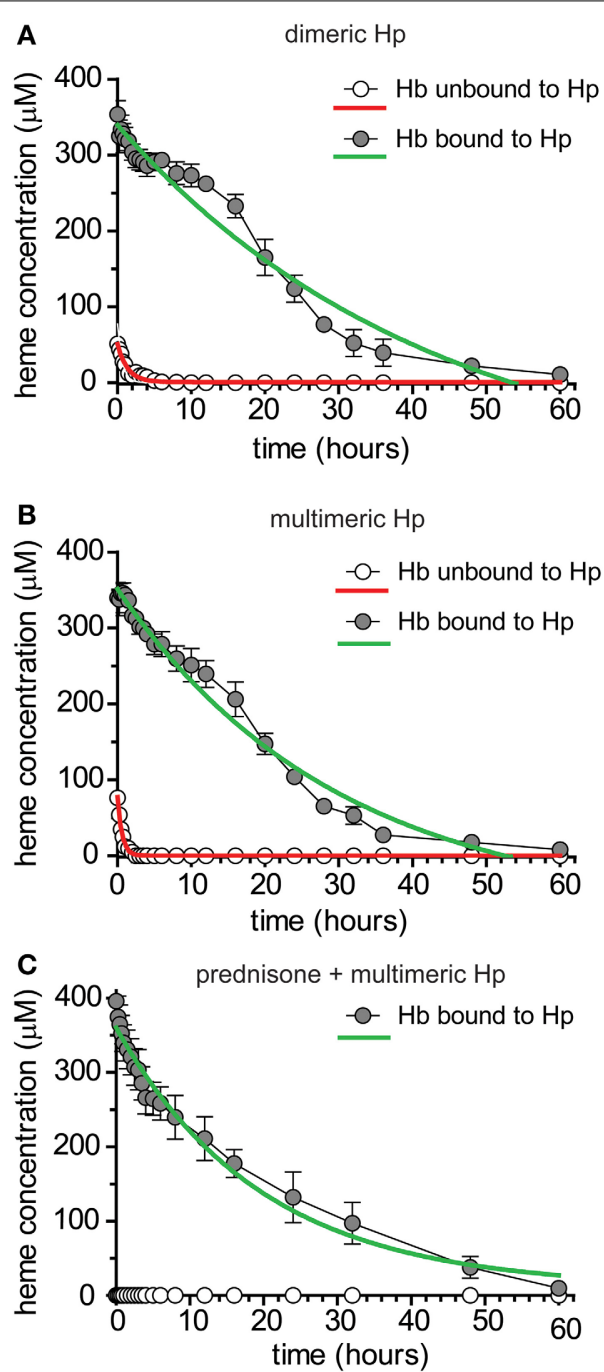

FIGURE 4 | Pharmacokinetics of human $\mathrm{Hb}$ following administration of dimeric or multimeric $\mathrm{Hp} \pm$ glucocorticoid up-regulation of $\mathrm{Hb}$

clearance systems. (A) Mean \pm SEM plasma concentration vs. time plotted for human purified $\mathrm{Hb}+$ human purified dimeric $\mathrm{Hp}$ administered to beagle dogs $(n=6)$. Data are fitted to a single exponential decay (red and green traces) and represent total heme bound to $\mathrm{Hb}+\mathrm{Hb}: \mathrm{Hp}$.

Pharmacokinetic parameter estimates are shown in Table 3. (B) Mean \pm SEM plasma concentration vs. time plotted for human purified $\mathrm{Hb}+$ human purified multimeric $\mathrm{Hp}$ administered to beagle dogs $(n=6)$. Data are fitted to a single exponential decay (red and green traces) and represent total heme bound to $\mathrm{Hb}+\mathrm{Hb}: \mathrm{Hp}$. Pharmacokinetic parameter estimates are shown in Table 3. (C) Mean \pm SEM plasma concentration vs. time plotted for prednisone pre-treated Beagle dogs administered human purified $\mathrm{Hb}+$ human purified multimeric $\mathrm{Hp}(n=6)$. Gray circles represent $\mathrm{Hb}: \mathrm{Hp}$ complex and open circles represent unbound $\mathrm{Hb}$. No unbound $\mathrm{Hb}$ was detected, as result data is set to zero. Data are fitted to a single exponential decay (red and green traces) and represent total heme bound to $\mathrm{Hb}+$ $\mathrm{Hb}$ :Hp. Pharmacokinetic parameter estimates are shown in Table 4.

of dimeric and multimeric Hb:Hp complexes by CD163 (Asleh et al., 2003, 2014; Lipiski et al., 2013). Our in vivo data suggest that in a setting of acute therapeutic $\mathrm{Hp}$ administration the phenotype composition of a product will most likely not determine clearance and cumulative exposure. The endogenous dog $\mathrm{Hp}$ is only expressed in a dimeric composition without other Hps similar to the 2-1 or 2-2 phenotypes found in humans (Mominoki et al., 1995). Moreover different glycosylation patterns exist between dog and human Hp (Mominoki et al., 1995) and this could potentially contribute to altered CD163 receptor interactions. Given these known differences it is notable that highly comparable exposure times and clearance rates are observed in Beagle dogs with Hp proteins novel to the species. This observation supports that the $\mathrm{Hb}: \mathrm{Hp}$ clearance system is conserved among non-rodent animal species and human.

Second, data from Figures 1, 2 clearly demonstrate that the function and regulation of the dog macrophage $\mathrm{Hb}: \mathrm{Hp}$ clearance system is comparable to the human system. Both systems are specific to the Hb:Hp complex as opposed to free Hp (Kristiansen et al., 2001). This specificity of the clearance system for the complex helps to preserve high circulating $\mathrm{Hp}$ concentrations. Additionally, the expression of the clearance system as well as its down-stream effector pathways is strongly stimulated by glucocorticoid treatment of peripheral blood monocytes (Schaer et al., 2002, 2008). In human, the glucocorticoid stimulation of $\mathrm{Hb}: \mathrm{Hp}$ uptake triggers a complex differentiation pathway that promotes monocyte differentiation into an anti-oxidative and iron handling macrophage phenotype during increased extracellular Hb exposure (Vallelian et al., 2010). Glucocorticoid stimulation of $\mathrm{Hb}: \mathrm{Hp}$ uptake by peripheral blood monocytes could also enhance total body $\mathrm{Hb}: \mathrm{Hp}$ clearance capacity, however this has not been investigated so far. Our pharmacokinetic data suggest that glucocorticoid stimulation of the peripheral blood monocyte $\mathrm{Hb}: \mathrm{Hp}$ clearance system does not significantly enhance systemic $\mathrm{Hb}$ clearance, which appears to be predominantly mediated by resident tissue macrophages in the liver and spleen. These cells already express maximum levels of CD163 and high HO-1 enzymatic capacity under physiologic conditions (Zwadlo et al., 1987).

\section{STUDY LIMITATIONS}

The shortcomings of this study are clearly that no data exists to compare dog to human in terms of pharmacokinetics of $\mathrm{Hb}: \mathrm{Hp}$ complexes following exogenous administration during hemolysis. In the future human studies evaluating the pharmacokinetics of $\mathrm{Hb}: \mathrm{Hp}$ will provide important information that will contribute to the appropriate dosing and potential safety concerns associated with long circulating $\mathrm{Hb}: \mathrm{Hp}$ complexes if saturable pharmacokinetics are found to occur. Based on our data in dogs, $\mathrm{Hb}: \mathrm{Hp}$ complexes are cleared more rapidly than in rodent species.

\section{NOVELTY}

The novelty of the data presented identify the Beagle dog as relevant species that may provide a better understanding of $\mathrm{Hb}: \mathrm{Hp}$ clearance in humans. These findings are applicable to recent interests in developing plasma derived $\mathrm{Hp}$ as a biologic therapeutic for uses in both acute and chronic hemolytic disease states and provide data to support pharmacologic and pharmacokinetic similarity for predicting human safety. The data from dogs follow single compartment pharmacokinetics with a Vc limited to the plasma compartment. The clearance from the plasma compartment is slower than for Hb however much more rapid 
Table 4 | Pharmacokinetic parameters $\mathrm{Hb}$ bound to multimeric $\mathrm{Hp}$ (mean \pm SEM) following prednisone treatment in Beagles.

\begin{tabular}{|c|c|c|c|c|c|}
\hline Hemoglobin [heme] & $C_{\max }(\mu \mathrm{mol} / \mathrm{L})$ & $\mathrm{AUC}_{0 \text {-infinity }}\left(\mathrm{h}^{*} \mu \mathrm{mol} / \mathrm{L}\right)$ & $\mathrm{CL}(\mathrm{L} / \mathrm{h})$ & $V c(\mathrm{~L})$ & $t_{1 / 2}(\mathrm{~h})$ \\
\hline Human Hb (bound) & $397.0 \pm 33.6$ & $6534 \pm 100$ & $0.04185 \pm 0.00587$ & $0.6469 \pm 0.0511$ & $12.17 \pm 0.157$ \\
\hline
\end{tabular}

(Unbound) and (bound) to Hp, - no free (unbound) Hb detected.

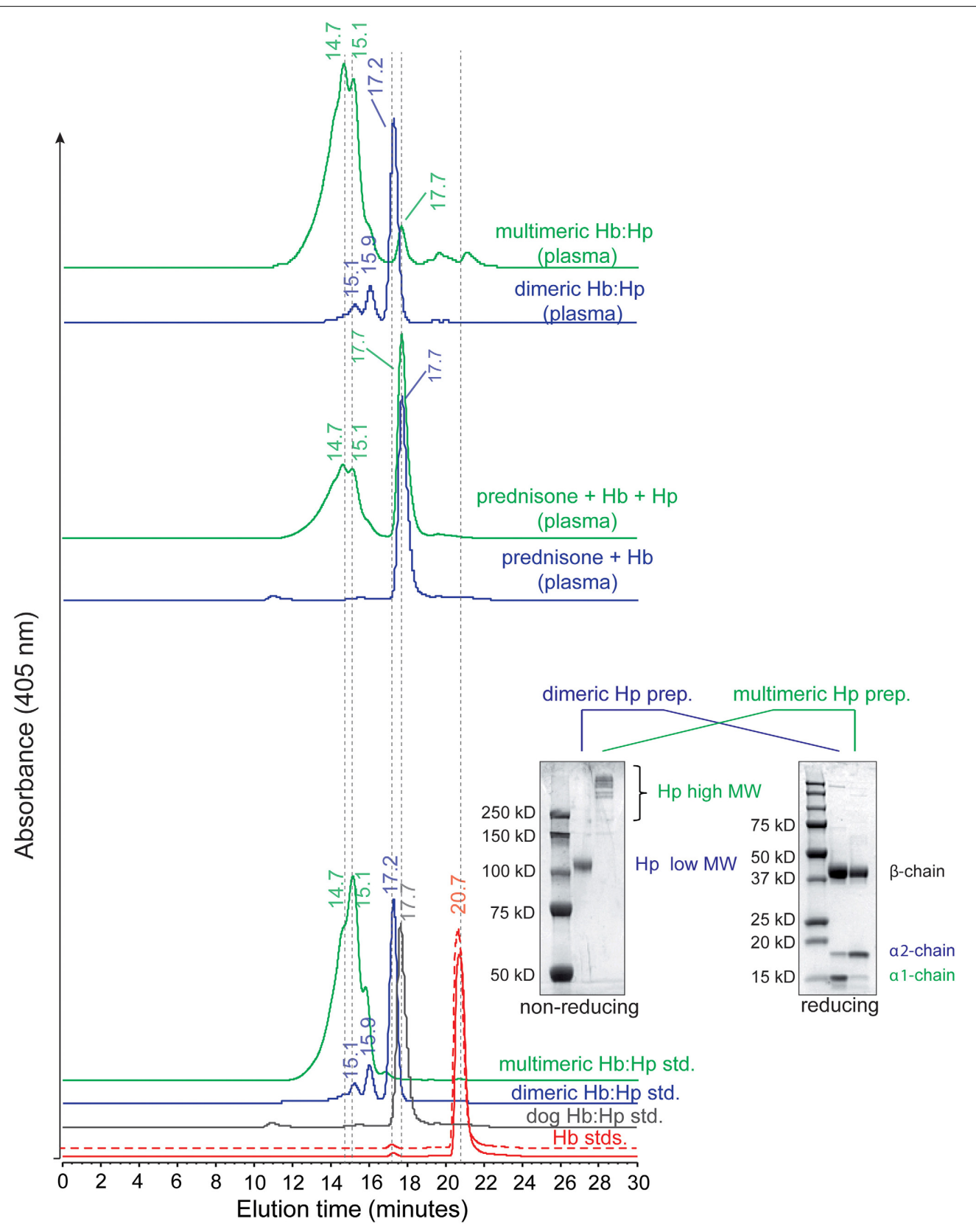

FIGURE 5 | Plasma profiles of bound $\mathrm{Hb}: \mathrm{Hp}$ complexes. (Bottom panel) $\mathrm{SEC}$ elution profiles of standard human $\mathrm{Hb}$ (solid red line), dog $\mathrm{Hb}$ (dashed red line) and $\mathrm{Hb}: \mathrm{Hp}$ complexes. Bottom panel inset shows gel electrophoresis of dimeric and multimeric $\mathrm{Hp}$ preparations under non-reducing and reducing conditions. (Middle panel) shows representative plasma samples from prednisone pre-treated animals following $\mathrm{Hb}$ exposure $( \pm)$ multimeric $\mathrm{Hp}$. (Top panel) shows the distribution of $\mathrm{Hb}$ bound to $\mathrm{Hp}$ after dimeric and multimeric human $\mathrm{Hp}$ dosing. 
than in rodent species (Lipiski et al., 2013). We speculate that more rapid pharmacokinetic clearance in vivo and the evidence of cellular clearance in vitro suggest that the dog may be translatable to human. The identification of a non-rodent animal model may also prevent the need for genetic modifications to humanize the clearance pathway of animal species to enhance human predictability.

\section{ACKNOWLEDGMENTS}

We would like to thank Joan Dalton and her research group, Bio Products Laboratory as well as Nathan Brinkman and his research group, CSL Behring for their efforts in the preparation of human plasma purified haptoglobins. This study was funded by FDA internal funding to Paul W. Buehler and by the Swiss National Science Foundation (grants 310030/120658 and 31003A/138500 to Dominik J. Schaer), the University of Zurich Research Priority Program "Integrative Human Physiology" and the Swiss Federal Commission for Technology and Innovation (CTI).

\section{REFERENCES}

Andersen, C. B., Torvund-Jensen, M., Nielsen, M. J., de Oliveira, C. L., Hersleth, H. P., Andersen, N. H., et al. (2012). Structure of the haptoglobin-haemoglobin complex. Nature 489, 456-459. doi: 10.1038/nature 11369

Asleh, R., Marsh, S., Shilkrut, M., Binah, O., Guetta, J., Lejbkowicz, F., et al. (2003). Genetically determined heterogeneity in hemoglobin scavenging and susceptibility to diabetic cardiovascular disease. Circ. Res. 92, 1193-1200. doi: 10.1161/01.RES.0000076889.23082.F1

Asleh, R., Ward, J., Levy, N. S., Safuri, S., Aronson, D., and Levy, A. P. (2014). Haptoglobin Genotype-dependent Differences in Macrophage Lysosomal Oxidative Injury. J. Biol. Chem. 289, 16313-16325. doi: 10.1074/jbc.M114.554212

Baek, J. H., D’Agnillo, F., Vallelian, F., Pereira, C. P., Williams, M. C., Jia, Y., et al. (2012). Hemoglobin-driven pathophysiology is an in vivo consequence of the red blood cell storage lesion that can be attenuated in guinea pigs by haptoglobin therapy. J. Clin. Invest.122, 1444-1458. doi: 10.1172/JCI 59770

Boretti, F. S., Buehler, P. W., D’Agnillo, F., Kluge, K., Glaus, T., Butt, O. I., et al. (2009). Sequestration of extracellular hemoglobin within a haptoglobin complex decreases its hypertensive and oxidative effects in dogs and guinea pigs. J. Clin. Invest. 119, 2271-2280. doi: 10.1172/JCI 39115

Connell, G. E., Dixon, G. H., and Smithies, O. (1962). Subdivision of the three common haptoglobin types based on 'hidden' diffrences. Nature 193, 505-506. doi: 10.1038/193505a0

Eda, K., Ohtsuka, S., Seo, Y., Yamada, S., Ishiyama, M., Miyamoto, T., et al. (2001). Conservative treatment of hemolytic complication following coil embolization in two adult cases of patent ductus arteriosus. Jpn. Circ. J. 65, 834-836. doi: $10.1253 /$ jcj.65.834

Granfeldt, A., Hvas, C. L., Graversen, J. H., Christensen, P. A., Petersen, M. D., Anton, G., et al. (2013). Targeting dexamethasone to macrophages in a porcine endotoxemic model. Crit. Care Med. 41, e309-e318. doi: 10.1097/CCM.0b013e31828a45ef

Hashimoto, K., Nomura, K., Nakano, M., Sasaki, T., and Kurosawa, H. (1993). Pharmacological intervention for renal protection during cardiopulmonary bypass. Heart Vessels. 8, 203-210. doi: 10.1007/BF017 44743

Kaempfer, T., Duerst, E., Gehrig, P., Roschitzki, B., Rutishauser, D., Grossmann, J., et al. (2011). Extracellular hemoglobin polarizes the macrophage proteome toward Hb-clearance, enhanced antioxidant capacity and suppressed HLA class 2 expression. J. Proteome Res. 10, 2397-2408. doi: 10.1021/pr10 $1230 \mathrm{y}$

Kristiansen, M., Graversen, J. H., Jacobsen, C., Sonne, O., Hoffman, H. J., Law, S. K., et al. (2001). Identification of the haemoglobin scavenger receptor. Nature 409, 198-201. doi: 10.1038/35051594
Levy, A. P., Asleh, R., Blum, S., Levy, N. S., Miller-Lotan, R., Kalet-Litman, S., et al. (2010). Haptoglobin: basic and clinical aspects. Antioxid. Redox Signal. 12, 293-304. doi: 10.1089/ars.2009.2793

Lipiski, M., Deuel, J. W., Baek, J. H., Engelsberger, W. R., Buehler, P. W., and Schaer, D. J. (2013). Human Hp1-1 and Hp2-2 phenotype-specific haptoglobin therapeutics are both effective in vitro and in guinea pigs to attenuate hemoglobin toxicity. Antioxid. Redox Signal. 19, 1619-1633. doi: 10.1089/ars.2012. 5089

Martinez-Subiela, S., Ginel, P. J., and Ceron, J. J. (2004). Effects of different glucocorticoid treatments on serum acute phase proteins in dogs. Vet. Rec. 154, 814-817. doi: 10.1136/vr.154.26.814

Mominoki, K., Nakagawa-Tosa, N., Morimatsu, M., Syuto, B., and Saito, M. (1995). Haptoglobin in Carnivora: a unique molecular structure in bear, cat and dog haptoglobins. Comp. Biochem. Physiol. B. Biochem. Mol. Biol. 110, 785-789.

Nosslin, B. F., and Nyman, M. (1958). Haptoglobin determination in diagnosis of haemolytic diseases. Lancet 1, 1000-1001. doi: 10.1016/S0140-6736(58) 91804-X

Palmer, A. F., Sun, G., and Harris, D. R. (2009). Tangential flow filtration of hemoglobin. Biotechnol. Prog. 25, 189-199. doi: 10.1002/ btpr.119

Schaer, C. A., Schoedon, G., Imhof, A., Kurrer, M. O., and Schaer, D. J. (2006a). Constitutive endocytosis of CD163 mediates hemoglobin-heme uptake and determines the noninflammatory and protective transcriptional response of macrophages to hemoglobin. Circ. Res. 99, 943-950. doi: 10.1161/01.RES.0000247067.34173.1b

Schaer, C. A., Vallelian, F., Imhof, A., Schoedon, G., and Schaer, D. J. (2008). Heme carrier protein (HCP-1) spatially interacts with the CD163 hemoglobin uptake pathway and is a target of inflammatory macrophage activation. J. Leukoc. Biol. 83, 325-333. doi: 10.1189/jlb.0407226

Schaer, D. J., Alayash, A. I., and Buehler, P. W. (2007). Gating the radical hemoglobin to macrophages: the anti-inflammatory role of CD163, a scavenger receptor. Antioxid. Redox Signal. 9, 991-999. doi: 10.1089/ars. 2007.1576

Schaer, D. J., Boretti, F. S., Hongegger, A., Poehler, D., Linnscheid, P., Staege, H., et al. (2001). Molecular cloning and characterization of the mouse CD163 homologue, a highly glucocorticoid-inducible member of the scavenger receptor cysteine-rich family. Immunogenetics 53, 170-177. doi: 10.1007/s002510100304

Schaer, D. J., Boretti, F. S., Schoedon, G., and Schaffner, A. (2002). Induction of the CD163-dependent haemoglobin uptake by macrophages as a novel antiinflammatory action of glucocorticoids. Br. J. Haematol. 119, 239-243. doi 10.1046/j.1365-2141.2002.03790.x

Schaer, D. J., and Buehler, P. W. (2013). Cell-free hemoglobin and its scavenger proteins: new disease models leading the way to targeted therapies. Cold Spring Harb. Perspect. Med. 6, 1-18. doi: 10.1101/cshperspect. a013433

Schaer, D. J., Buehler, P. W., Alayash, A. I., Belcher, J. D., and Vercellotti, G. M. (2013). Hemolysis and free hemoglobin revisited: exploring hemoglobin and hemin scavengers as a novel class of therapeutic proteins. Blood 121, 1276-1284. doi: 10.1182/blood-2012-11-451229

Schaer, D. J., Schaer, C. A., Buehler, P. W., Boykins, R. A., Schoedon, G., Alayash, A. I., et al. (2006b). CD163 is the macrophage scavenger receptor for native and chemically modified hemoglobins in the absence of haptoglobin. Blood 107, 373-380. doi: 10.1182/blood-2005-03-1014

Smithies, O., Connell, G. E., and Dixon, G. H. (1962a). Chromosomal rearrangements and the evolution of haptoglobin genes. Nature 196, 232-236.

Smithies, O., Connell, G. E., and Dixon, G. H. (1962b). Inheritance of haptoglobin subtypes. Am. J. Hum. Genet. 14, 14-21.

Vallelian, F., Schaer, C. A., Kaempfer, T., Gehrig, P., Duerst, E., Schoedon, G., et al. (2010). Glucocorticoid treatment skews human monocyte differentiation into a hemoglobin-clearance phenotype with enhanced heme-iron recycling and antioxidant capacity. Blood 116, 5347-5356. doi: 10.1182/blood-2010-04277319

Winterbourn, C. C. (1985). CRC Handbook of Methods of Oxygen Radical Research. Boca Raton, FL: CRC Press.

Yamamoto, H., Nishikawa, S., Yamazaki, K., and Kudo, R. (2000). Efficacy of haptoglobin administration in the early postoperative course of patients 
with a diagnosis of HELLP syndrome. J. Obstet. Gynaecol. 20, 610-611. doi: $10.1080 / 01443610020001459$

Zwadlo, G., Voegeli, R., Schulze Osthoff, K., and Sorg, C. (1987). A monoclonal antibody to a novel differentiation antigen on human macrophages associated with the down-regulatory phase of the inflammatory process. Exp. Cell Biol. 55, 295-304.

Conflict of Interest Statement: The authors declare that the research was conducted in the absence of any commercial or financial relationships that could be construed as a potential conflict of interest.

Received: 30 July 2014; accepted: 18 September 2014; published online: 09 October 2014.
Citation: Boretti FS, BaekJH, Palmer AF, Schaer DJ and Buehler PW (2014) Modeling hemoglobin and hemoglobin:haptoglobin complex clearance in a non-rodent speciespharmacokinetic and therapeutic implications. Front. Physiol. 5:385. doi: 10.3389/ fphys.2014.00385

This article was submitted to Oxidant Physiology, a section of the journal Frontiers in Physiology.

Copyright (c) 2014 Boretti, Baek, Palmer, Schaer and Buehler. This is an openaccess article distributed under the terms of the Creative Commons Attribution License (CC BY). The use, distribution or reproduction in other forums is permitted, provided the original author(s) or licensor are credited and that the original publication in this journal is cited, in accordance with accepted academic practice. No use, distribution or reproduction is permitted which does not comply with these terms. 